\title{
The Role of Drinking Water Shortages on Human Psychological Functioning
}

\section{SIAMAK KHODARAHIMI ${ }^{1}$, ABDOLRAHMAN RAHIMIAN BOOGAR ${ }^{2}$ and CHERYL-ANNE JOHNSTON ${ }^{3}$}

\author{
${ }^{1}$ Eghlid Branch, Islamic Azad University, Iran. \\ 2Universality of Zabol, Iran. \\ ${ }^{3}$ Independent Researcher; South Africa.
}

http://dx.doi.org/10.12944/CWE.9.2.03

(Received: May 16, 2014; Accepted: July 11, 2014)

\begin{abstract}
This study is grounded on an ecopsychological approach towards the effect of water shortages on human psychological functioning. The purpose of this study was to: (1) to examine the prevalence of psychological problems in rural residents with and without water shortages; (2) to evaluate human attributions about the possible causes of water scarcity; (3) to explore human coping styles towards water shortage; and (4) to recognize the role of sociocultural factors on the aforesaid factors. Participants included 3850 Iranian rural residents, those with water shortages (WWS), and those without water shortages (WOWS). A demographic questionnaire and several selfrating measures were used. Resulting data indicates that the prevalence of mental health problems is significantly higher in rural residents who suffer with water shortages. Attributional styles towards water shortages consisted of four components: personal, social, natural, and organizational. Coping styles of participants (with water shortages) indicated an emotional-avoidant coping style, the utilization of water consumption methods to optimize water usage, the use of water-free technologies, social adaptation to life with regards to water, and the application of high quality technologies for water saving. Demographic and sociocultural factors influence psychological functioning with regards to water scarcity. This study demonstrates that mental health problems are more prevalent in areas with water shortages. It also indicates the impact of attributional styles, coping methods and the role of demographic and sociocultural factors on psychological functioning when water shortages occur.
\end{abstract}

Key words: drinking water shortage; Human psychological functioning; Attributional style; Mental health; Coping style.

\section{INTRODUCTION}

The impact of climate change on water resources is the subject of much research and debate, with other factors such as over population also influencing the availability of water resources. Drinking water is essential for life. Of concern, is how access to drinkable water will impact on humans. The majority of people on Earth will experience severe pressure with regards to fresh water availability as a consequence of climate change ${ }^{1}$. Factors such as climate change, industrialization, and over population may already be impacting on fresh drinking water resources. This is likely to cause an increase in the frequency and severity of droughts and water scarcity. More than 3.4 million people die each year from utilizing polluted water sources and from unsafe drinking water factors; particularly in the developed world ${ }^{2}$. In addition, nations in the Middle East and North Africa could face potentially catastrophic water disasters in the near future ${ }^{1}$. According to Iranian officials this potential for disaster may occur in Iran too ${ }^{2}$. Therefore, the purpose of this study is to investigate human psychological responses to water shortages in an Iranian sample. 
In the field of drought and psychology, there is substantial international literature about the role of drought on mental health and psychopathology in rural residents who live in drought-affected regions ${ }^{3-6}$. However, there is limited research about the effect of drinking water shortages on human psychological functioning. The present study is grounded on natural disasters, stress, worry, attributional styles and emotion theories ${ }^{10-16}$.

In line with the aforementioned theories, the present study suggests that people perceive water shortages as a natural disaster which threatens their very existence, and not merely as a source of general stress.

Psychological functioning in relation to water scarcity is therefore investigated with this in mind. Psychological functioning includes four constructs: mental health problems, perceivedstress, worry and negative emotions. The role of water shortages on mental health among humans is a relatively well-known issue; however its effect on perceived stress, worry and negative emotions is not as well known and forms the exploratory aspect of this study. It is hypothesized in this study, that human psychological responses towards drinking water shortages are different to human reactions to loss and catastrophic traumas. Therefore, the present study speculates that psychological responses to water shortages could be explained according to the attribution of its causality, human reactions to this disaster, and the role of cultural elements toward this phenomenon, and possible solutions for its management and control. According to the aforesaid theories and literature; the present study has four aims: (1) to examine the prevalence of psychological problems in rural residents with and without water shortages; (2) to evaluate human attributions about the possible causes of water scarcity; (3) to explore human coping styles toward water shortages; and (4) to recognize the role of sociocultural factors on the aforesaid constructs. The first hypothesis is that the prevalence of psychological problems in rural residents with water shortages (WWS) is greater than rural residents without water shortages (WOWS). The second hypothesis of this study is that attributional style towards the cause and effect of water shortages is a multifaceted construct. The third hypothesis of this study is that coping style towards water shortages is a multifaceted construct in this sample. The fourth hypothesis of this study is that sociocultural factors (i.e. age, gender, the level of education, occupation, ethnicity, marital status, monthly income, the family size, city and village of residence) would have a significant influence on attributional and coping styles towards water shortages in this sample.

\section{Method \\ Participants}

The participants were 4180 rural residents from two regions: Darab and Zarindasht; and Eghlid cities, Fars province, Iran. A total of 330 individuals' data was removed due to their invalid responses to the measures. Participants in the group with drinking water shortages (WWS) were 3690 rural residents from 57 villages around Darab and Zarindasht cities, from the southern of Fars province. Participants in the Group without drinking water shortages (WOWS) were 160 rural residents from Dejkord district around Eghlid and Sarhad-e-Chahar Dange, the northern of Fars province. This sample included 1927 males and 1923 females. The total sample of rural residents consisted of 3850 participants. The mean (and standard deviation) of the age of the total sample was $41.90(S D=8.13)$. Participants were selected from all the villages in and separated into two groups using the random sampling method. As an incentive, they received psychological consultations to assist in adaptation to water scarcity, as well as technological information about drinking water equipment. This sample was recruited from all those villages with more than 10 families around the aforesaid cities. After informed consent was acquired, participants completed a questionnaire containing several sections on background information, and six selfrating inventories.

\section{Instruments}

The demographic questionnaire included items on age, gender, marital status, ethnicity, educational level, job status, number of family members, monthly income, monthly drinking water usage, monthly water price, and the city and village of residence.

Nine inventories were used: (1) Attributional Scale of Water Shortage Causes (ASWSC), (2) the Positive and Negative Affect Schedule (PANAS ${ }^{17}$ ), 
(3) the General Health Questionnaire 28 (GHQ$\left.28^{18}\right)$, (4) the Ahwaz Worry Inventory (AWI ${ }^{17}$ ), (5) the Perceived Stress Scale (PSS ${ }^{19}$ ), and (6) the Coping Styles with Drink Water Crisis (CSDWS ${ }^{8}$ ). The PANAS contains 20 items which include a positive affect (PANAS-P; 10 items) and a negative affect (PANAS-N; 10 items). Each item is rated on a 5 -point Likert scale ranging from 1 (very slightly or not at all) to 5 (very much or extremely). There has been considerable support for the construct validity of the PANAS. The GHQ-28 is a 28 item and a selfadministered screening scale that measures four factors: somatic symptoms, anxiety and insomnia, social dysfunction, and severe depression. AWI consists of 20 items with four possible answers that include "always, "often", "sometimes" and "never" with numerical values of 3, 2, 1, and 0 respectively, and its scores range from 0 to 60 . PSS is a 10 -item scale and each item is rated on a 5-point scale ranging from never (0) to almost always (4). The CSDWS was developed to identify types of coping styles towards drinking water shortages in rural residents in the time of drought. All tests were administered in the Persian language. After reading the Informed Consent Form, all participants had the opportunity to ask any questions about the study before signing the informed consent.

\section{RESULTS}

To examine the first hypothesis several calculations for the prevalence rate of psychological problems were conducted with water shortages as the independent variable and mental health problems, stress, worry and negative emotions as dependent variables in this sample (table 1).

The initial data analysis related to the second hypothesis included an exploratory factor analysis that was conducted to examine the potential factors in the ASWSC. Principal factor analysis with varimax rotation was used to determine the construct validity of the ASWSC, and this analysis considered eignvalues higher than 1. Factor analysis specification was satisfactory, $K M O=.86$, Bartlett's Test of Sphericity $=.982, d f=508, p=.0001$, Rotation Sums of Squared Loadings $=72.46$. Factor analysis indicated that ASWSC consisted of four factors and eigenvalues for nine factors ranging from 1 to 5.49 . These four factors explained a total of $72.46 \%$ of the variance. These factors included: (1) personal, (2) social, (3) natural, and (4) organizational attribution styles.

To examine the third hypothesis, a confirmatory factor analysis was conducted to examine the potential factors in the CSDWS. Principal factor analysis with varimax rotation was computed to determine the construct validity of the CSDWS, and this analysis considered eigenvalues higher than 1. Factor analysis specification was satisfactory, $K M O=.85$, Bartlett's Test of Sphericity= $.984, d f=516, p=.0001$, Rotation Sums of Squared Loadings $=75.66$. Table 1 shows the significantly rotated correlation of higher than .30 for 52 items in 15 iterations. Factor analysis indicated that CSDWS

Table 1 : The Prevalence Rate of Psychological Problems in Rural Residents with and without Water Shortage

\begin{tabular}{llcc}
\hline \multicolumn{1}{c}{ Psychological Problems } & $\begin{array}{c}\text { Rural Residents with } \\
\text { Water Shortage }\end{array}$ & $\begin{array}{c}\text { Rural Residents without } \\
\text { Water Shortage }\end{array}$ \\
\hline Mental & Somatic Complaints & 29.2 & 1.2 \\
Health & Anxiety/Insomnia & 27.6 & 1.1 \\
Problems & Social Dysfunction & 51.7 & 1.3 \\
& Depression & 11.6 & 0.2 \\
& Total Mental Health & 20.7 & 0.8 \\
Perceived Stress & Problems & 10.7 & 0.4 \\
Worry & & 24.1 & 1.3 \\
Negative Emotions & 17.78 & 0.6 \\
\hline
\end{tabular}


Table 2: The Effects of Demographic and Socio-cultural Factors on Attribution Style, Psychological Problems, Negative Emotions, Stress and Worry in the Total Sample

\begin{tabular}{lcccc}
\hline Independents & Wilks'k & F & df & p \\
\hline City & .549 & 95.24 & 28,7 & .0001 \\
Region & .976 & 6.48 & 14,3 & .0001 \\
Village & .123 & 9.59 & 868,5 & .0001 \\
Age & .206 & 11.91 & 518,4 & .0001 \\
Gender & .893 & 31.36 & 14,3 & .0001 \\
Marital Status & .971 & 3.95 & 28,7 & .0001 \\
Education & .709 & 13.25 & 98,2 & .0001 \\
Occupation & .753 & 15.35 & 70,1 & .0001 \\
Monthly Income & .742 & 16.78 & 70,1 & .0001 \\
Family Size & .739 & 13.61 & 84,2 & .0001 \\
Ethnicity & .868 & 12.71 & 42,1 & .0001 \\
\hline
\end{tabular}

consisted of four factors and eigenvalues for nine factors ranged from 1 to 5.49 . These four factors explained $75.66 \%$ of the variance. These factors included: (1) optimizing water consumption methods, (2) water-free technologies and social changes in life, (3) application of high quality technologies for water saving, and (4) emotional-avoidant styles.

To evaluate the fourth hypothesis with regards to the influence of the independent variables from the sociocultural and demographic category, a multivariate analysis of variance (MANOVA) was computed. The Independent variables considered were age, gender, the level of education, occupation, ethnicity, marital status, monthly income, the family size, city and village of residence; whilst the dependent variables considered were attribution styles, psychological problems (i.e. mental health problems, stress, worry and negative emotions) and coping styles (with water shortages). An overall multivariate analysis demonstrated the significant effects of age, gender, educational level, occupation, ethnicity, marital status, monthly income, the family size, city and village of residence (independent variables) on the specified dependent variables (table 2).

\section{DISCUSSION}

Results from the first hypothesis in this study showed that the prevalence of mental health problems, stress and worry is significantly higher in WWS rural residents compared to WOWS residents. These findings are consistent with previous research that indicates the role of drought and water shortages on the mental health of rural residents ${ }^{2-8}$. In addition, these findings are congruent with predictions of ecopsychology relating to natural disasters, stress, worry and emotions ${ }^{10,11,14,21,22}$. These findings demonstrate the human-nature interaction in the field of mental health and psychopathology. Therefore natural hazards such as water shortages may reduce human adaptation and, in turn, increase the probability of developing mental disorders.

Results from the second hypothesis indicated that the attributional style toward water shortages is a multidimensional construct with four subscales. These factors included: (1) personal, (2) social, (3) natural, and (4) organizational attributional styles. These findings show that the meaning of water shortages, (based on an individual's approach) motivates people to find a cause and then apply an explanation based on his/her knowledge of the environment. For causal explanations and effect inferences about water shortages, people look for attributions related to the behaviors of others, organizations, and themselves. These findings are congruent with predictions of attributional theory about cause and effect inferences of different physical and social events ${ }^{21}$. This study shows the application of attributional theory when understanding and managing natural disasters such as water shortages. Also, this study suggests that the nature of cause and effect inferences about water shortages may be influenced by sociocultural factors such as gender, ethnicity, and so forth that need further investigation. In practice, the present finding may be of value in creating an efficient program about water shortages at a community level. This result may prove useful for developing strategies that will ensure that people conserve water resources in rural regions. Therefore people with information may then have personal, social and organizational attributions about the causality of water shortages which provide options on how to change their lifestyles with regards to water consumption and how to prompt water conservation at social level; and will assist them to make social and organizational institutions more responsible about water management and conservation. 
Results from the third hypothesis in this study using confirmatory factor analysis confirmed the previous structure of coping style with regards to water shortages. This factor structure includes four levels of factors: (1) optimizing water consumption methods, (2) water-free technologies and social changes in life, (3) application of high quality technologies for water saving, and (4) emotionalavoidant styles. This result is in line with previous literature ${ }^{8}$. Also, this finding may be explained in line with stress and coping theory ${ }^{12}$. This study suggests that social and personal changes in life style are essential for efficient coping with water shortages in drought-affected regions. This study explores the necessity of changes in primary and secondary appraisal when people encounter a chronic and slow form of natural disaster such as water shortages. According to theses findings, people should be changing their personal and familial life styles towards a standardized procedure for water consumption. For example, they should only use drinking water inclusively for drinking purposes rather than for car washing, horticulture and agriculture purposes. Also, they may teach the standard usage of drinking water to children by the application of modeling and behavior modification principles. People can adapt some of their social rituals to reduce the irrational use of drinking water, particularly rituals about weddings and funerals in the rural regions. In addition, most of the water equipment in the rural areas is old and inefficient for water preservation purposes. Rural residents could use a few modern and standard water pops instead and they can teach these principles to their children and families. Finally, these findings show that people should be educated about the fact that water shortages are real and they can not cope with it by emotional and avoidant styles such as substance abuse, mystery and prayer.

Results from the fourth hypothesis demonstrated the role of demographics and socio-cultural factors on psychological problems and coping styles toward water shortages in the total sample. Results showed that WOWS rural residents have significantly lower levels of psychological problems, stress and worry and a significantly greater performance in optimizing water consumption methods, water-free technologies and social changes in life, and application of high quality technologies for water saving compared to WWS residents. Individuals of 40-years-old and over have significantly higher levels of psychological problems and a greater use of successive coping style with water shortages, than individuals of a lower aged-range. Married people have higher psychological problems, stress and worry than single individuals. Females have greater psychological problems and a lower performance in rational coping with water shortages than males. Individuals with lower educational levels have higher psychological problems and lower performance in the application of a rational coping style with water shortages, compared to individuals with higher educational levels. Farmers, housewives and unemployed individuals have greater psychological problems than governmental employee and sellers. However, farmers, housewives and employed individuals tend to use rational coping styles in relation to water shortages than the unemployed and sellers. Lower income is linked with higher psychological problems and with the application of avoidantemotive coping with water shortages. Also, greater family size is linked to higher psychological problems and the higher use of rational coping toward water scarcity. People with Turkish ethnicity have higher psychological problems, and they use lower rational coping towards water shortages in comparison to Lour and Fars individuals. These findings are consistent with the studies that affirm the roles of sociocultural and demographic factors on psychological functions of individuals, under the conditions of natural hazards and disasters ${ }^{23-27}$. The influences of demographics and socio-cultural factors on mental health and coping towards water shortages in this study show the beneficial application of a cultural-oriented approach in the ecopsychology of natural disasters management.

In conclusion, the present study advocates an ecopsychological approach to the understanding and management of water shortage, because it explains the role of water shortages in the prevalence of psychological problems; multidimensional structure of attribution and coping styles towards water shortage; and the influences of demographics and socio-cultural factors on the aforesaid constructs in a sample of rural residents in Iran. These findings can be applied by clinicians and policy makers for assessment and intervention purposes of 
natural hazards in psychotherapeutic and social settings. This study recommends the training of ecopsychology elements to strengthen psychological function towardst water shortages among people in drought-affected regions. Moreover, these findings highlight the necessity of life style changes toward drinking water everywhere. However, the present study is limited because it relies on a survey design and the use of a few self-rating scales. Future investigations should examine the role of water shortage on physical health, social behaviors, creativity and innovation and life style in crosscultural samples within longitudinal designs.

\section{REFERENCES}

1. Sticklor, R. Next Middle East war will be over water. Christian Science Monitor. Retrieved 8 January 2014 from: http://gulfnews.com/ opinions/columnists/next-middle-east-warwill-be-over-water-1.1238021 (2013).

2. Deutsche Press Agentur. Water shortage threatens Iran. Retrieved 12 September 2011 from: http://reliefweb.int/node/83476

3. World Health Organization. Safer water, better health: Costs, benefits and sustainability of interventions to protect and promote health. Retrieved January 8, 2014 from: http://whqlibdoc.who.int/ publications/2008/9789241596435 eng.pdf (2008).

4. World Health Organization. Drought, instability cause mental illness in Somalia. Retrieved 12 September 2012 from http://www.hananews. org/WholeArticle. asp?artld=9843 (2011).

5. Chand, P. K., \& Murthy, P. Climate change and mental health. Regional Health Forum, 12, 43-48 (2008).

6. Coêlho, A. E. L., Adair, J. G., \& Mocellin, J. S. P. Psychological responses to drought in Northeastern Brazil. Interamerican Journal of Psychology, 38, 95-103 (2004).

7. Edwards, B. Gray, M. \& Hunter, B. The impact of drought on mental health and alcohol use. Australian Social Policy Conference: An Inclusive Society? Practicalities and Possibilities. July 9, Sydney (2009).

8. Khodarahimi, S., \& Dehghani, H. Hopefulness, Positive and Negative Emotions in Rural Residents with Drink Water Shortage: An Iranian Case Study. Problems of Psychology in the 21st Century, 3, 32-41 (2012).

9. Khodarahimi, S., Dehghani, H. \& Nikpourian, M. H. Mental Health and Coping Styles in Drinking Water Shortage-Affected Rural Residents of Fars Province. European Journal of Mental Health, 9, 68-86 (2014).
10. Roszak, T., Gomes, M.E., \& Kanner, A.D. Ecopsychology: Restoring the earth, healing the mind (Sierra Club Books, 1995).

11. Benight, C. C., \& Bandura, A . Social cognitive theory of posttraumatic recovery: The role perceived self-efficacy. Behaviour Research and Therapy, 42, 1129-1148 (2004).

12. Davey, G. C. L. A mood-as-input account of perseverative worrying. In G. C. L. Davey \& A. Wells (Eds.), Worry and its psychological disorders: Theory, assessment and treatment (pp. 217-238) (Wiley, 2006). doi:10.1002/9780470713143

13. Lazarus, R S. Stress and emotion: A new synthesis (Springer, 1999).

14. Myers, D. G. Social psychology (McGraw-Hill, 2008).

15. Randall, S. Loss and climate change: The cost of parallel narratives. Ecopsychology, 1, 118-129 (2009).

16. Wisner, B. P. Blaikie, T. Cannon, \& I. Davis. At risk: Natural hazards, people's vulnerability and disasters (2nd ed.) (Routledge, 2004).

17. Watson, D., Clark, L.A., \& Tellegen, A. Development and validation of brief measures of positive and negative affect: The PANAS scales. Journal of Personality and Social Psychology, 54, 1063-1070 (1988).

18. Goldberg, D. P. and Hillier, V. F. A scaled version of the General Health Questionnaire. Psychological Medicine, 9, 139-145 (1979).

19. Taghvaee, D. Construction and validation of worry measurement scale and it's relation with anxiety, depression and educational performance among university students in Islamic Azad University- Arak Branch. M. A.Thesis, Islamic Azad University- Arak Branch, Iran (1997).

20. Cohen, S., Karmarck, T., \& Mermelstein, R. A global measure of perceived stress. Journal of Health and Social Behavior, 24, 385-396 
(1983).

21. Aronson, E., Wilson, T.D. \& Akert, R.M. Social Psychology (Prentice Hall, 2003).

22. Fredrickson, B. L., \& Losada, M. Positive affect and the complex dynamics of human flourishing. American Psychologist, 60, 678686 (2005).

23. Vugt, M. V. Averting the tragedy of the commons : Using social psychological science to protect the environment. Current Directions in Psychological Science, 18, 169173 (2009).

24. Cheung, E.Y.L., Chan, E.Y.Y., \& Lin, C. L.Y. Post disaster mental health impact of ethnic minorities in rural China: results from mixed quantitative and qualitative studies. Paper presented at: The 13th World Congress on Public Health. Apr 23-27; Addis Ababa, Ethiopia (2012).
25. Ferris, E., Petz, D., \& Stark, C. Disaster Risk Management: A Gender-Sensitive Approach is a Smart Approach. In E. Ferris, D. Petz and C. Stark (Eds.), The year of resurring disasters: A review of natural disasters in 2012 (pp 71-88) (The Brookings Institution, 2013).

26. Kronenberg, M., et al. First responder culture: Implications for mental health professionals providing services following a natural disaster. Psychiatric Annals, 38, 114-118 (2008).

27. Siriwardhana, C., Pannala, G., Siribaddana, S., Sumathipala, A., \& Stewart, R. Impact of exposure to conflict, tsunami and mental disorders on school absenteeism: Findings from a national sample of Sri Lankan children aged $12-17$ years. BMC Public Health, 13, 1-9 (2013). 